\title{
A influência do escritório de projetos e da estrutura organizacional projetizada no alinhamento dos projetos de tecnologia da informação aos modelos de negócios
}

Luciene Diana Siqueira

Mestra Em Administração Pela Universidade Municipal De São Caetano Do Sul,São Paulo, Brasil

Luciene.Diana@Hotmail.Com

Sergio Feliciano Crispim

Doutor Em Administração Pela Usp; Docente Permanente Do Programa De PósGraduação Em Administração (M/D) Da Universidade Municipal De São Caetano Do Sul, São Paulo, Brasil

Scrispim@Uol.Com.Br

Marcos Antonio Gaspar

Doutor Em Administração Pela Usp; Docente Permanente Do Programa De PósGraduação Em Informática E Gestão Do Conhecimento (M/D) Da Universidade Nove De Julho, São Paulo, Brasil Marcos.Antonio@Uni9.Pro.Br 


\title{
Resumo
}

Esta pesquisa investigou os aspectos que norteiam a gestão de projetos de $\mathrm{TI}$ (sistemática formal do gerenciamento de projetos de TI, área responsável pelos projetos e estrutura organizacional). Foi realizada pesquisa exploratória-descritiva quantitativa com utilização do método levantamento de campo (survey). O questionário aplicado foi respondido por 327 profissionais atuantes em projetos de TI. Foram aplicadas técnicas estatísticas descritivas e univariadas, além da análise multivariada (CATPCA). Como principais resultados, observou-se que a formalização da sistemática de gestão de projetos de TI é um processo crescente nas organizações. A estrutura organizacional funcional ainda é a mais praticada, embora a estrutura 'projetizada' tenha conquistado espaço. O escritório de projetos (PMO) lidera como sendo a área que seleciona, prioriza e monitora projetos. Verificou-se ainda que o PMO e a estrutura organizacional 'projetizada' são aspectos positivos e significativos no alinhamento dos projetos de TI aos modelos de negócios.

Palavras-chave: Projetos de TI. Escritório de projetos. Estrutura organizacional.

\section{The influence of the project management office and the organizational projectized structure in the alignment of information technology projects to business models}

\begin{abstract}
This research aims to investigate some aspects around IT projects management (formal systematic of IT projects management; responsible area for projects and organization structure). It was performed an exploratory-descriptive research with application of a survey. The questionnaire was filled out by 327 IT project professionals. Descriptive statistics techniques and univariate analysis were applied, such as frequency distribution percentage, as well as multivariate analysis, specifically the exploratory technique CATPCA. The main results showed that a formal systematic of IT projects management is a growing solidification process within organizations, the functional organizational structure is still the most widely practiced, although the structure 'projectized' has conquered its space, presenting at the second position. The project management office (PMO) leads as the area which selects, prioritizes and monitors projects. It was also verified that the PMO and the 'projectized' organizational structure are positive and significant aspects in aligning IT projects to business models.
\end{abstract}

Key words: IT projects. Project management office. Organizational structure. 
La influencia de la oficina de gestión de proyecto y la estructura organizativa projectada en la alineación de los proyectos de tecnología de la información para modelos de negocio

\section{Resumen}

Esta pesquisa objetiva investigar aspectos que guía la gestión del proyectos (gestión de proyecto sistemática formal, responsable de proyectos y estructura organizativa). Se realizó una investigación exploratória-descriptiva cuantitativa usando el método de encuesta de campo (survey). 327 profesionales respondieron al cuestionario en proyectos. Se aplicaron técnicas de estadísticas descriptivas y univariadas como la distribución de frecuencia porcentual, además del análisis multivariado, específicamente la técnica exploratoria CATPCA. Como principales resultados, se observó que la formalización una sistemática de gestión de proyectos es un proceso en crecimiento en las organizaciones. La estructura organizacional funcional sigue siendo el más practicaban, aunque la estrutura 'proyectizda' ha conquistado su espacio. La oficina de gestión de proyectos (PMO) se conduce como el área seleccionar, priorizar y supervisar proyectos. Se encontró también que el PMO y la estructura organizacional son matricial débil aspectos positivos y significativos en la alineación de la TI proyectos de modelos de negocio.

Palabras clave: Proyectos de TI. Oficina de gestión de proyecto. Estructura de organización.

\section{Introdução}

Um dos maiores desafios da alta administração é desenvolver e aprimorar a habilidade de compor um portfólio de projetos que esteja alinhado ao modelo de negócio da organização, de modo a contribuir para o alcance dos resultados e benefícios delineados pela empresa. $O$ número de organizações que implanta escritórios de projetos está aumentando e a área de TI tem investido em gestão de projetos de forma mais profissional. As razões para esse crescimento são variadas: adoção de novas tecnologias, questões de conformidade regulamentar, terceirização e a premissa sempre presente para fazer mais com menos.

Além de instrumento operacional para a adaptação e evolução organizacional, o gerenciamento de projetos exerce importante papel estratégico, tanto para organizações que fazem uso de projetos para criar, aprimorar ou manter sua proposição de valor, quanto para organizações cujo negócio tem por competência essencial a comercialização de projetos. 
Os projetos são frequentemente usados como meio para viabilizar a execução das estratégias da organização (PMI, 2013). A questão do alinhamento estratégico é também mantida no nível de projeto, e a comissão de priorização de projetos garante a alocação de recursos de $\mathrm{Tl}$ apenas nos projetos alinhados aos objetivos organizacionais (Avison, Jones, Powell, \& Wilson, 2004).

A cultura organizacional, o estilo e a estrutura são fatores influenciadores da maneira como os projetos são priorizados, planejados e executados (Kerzner, 2006). Nesse contexto, é importante destacar o papel do PMO (Project Management Office) ou escritório de projetos, principalmente numa estrutura orientada a projetos ('projetizada'). Empresas de todo o mundo em diferentes setores têm cada vez mais aderido ao escritório de projetos. De acordo com dados divulgados pelo Project Management Institute (PMI) a respeito de empresas atuantes no Brasil, $46 \%$ dos respondentes citaram a existência de um PMO corporativo em sua organização, sendo que $56 \%$ afirmaram já existir PMOs específicos por área na organização. Não obstante, afirmaram ainda que a área de TI lidera o ranking com 57,2\% das afirmações dos respondentes, seguida pela área de Engenharia, com 41,4\% (Pmsurvey, 2011).

Diante deste contexto de importância crescente dos projetos de $\mathrm{Tl}$ como direcionadores de inovação nos modelos de negócios, do aumento da criação de escritórios de projetos e ainda das mudanças na estrutura organizacional, o seguinte problema de pesquisa é proposto: Qual a influência do escritório de projetos e da estrutura organizacional 'projetizada' no alinhamento dos projetos de tecnologia da informação aos modelos de negócios?

Na próxima seção é apresentado o referencial teórico balizador da presente pesquisa, com o consequente delineamento das hipóteses de pesquisa. $\mathrm{Na}$ sequência é exposta a metodologia adotada, seguida pela apresentação e discussão dos principais resultados obtidos na pesquisa de campo realizada. Por fim, as considerações finais são apresentadas. 


\section{Referencial Teórico}

\subsection{Alinhamento estratégico (ae) e modelo de negócio (mn)}

Segundo argumentação de Luftman, Zadeh, Derksen, Santana, Rigoni e Huang (2013), a temática alinhamento estratégico entre Negócios e Tecnologia da Informação pode ser considerada uma das principais preocupações de gestores nas organizações em todo o mundo. Estudos suportam a hipótese de que o alinhamento entre Estratégias de Negócios e TI melhora o desempenho empresarial (Almeida \& Santos, 2015; Siqueira \& Crispim, 2014; Freitas, Ferreira, Coutinho, \& Irigaray, 2013). Além disso, a ligação entre TI e modelos de negócios é particularmente forte, pois a TI tem sido um importante facilitador para uma grande variedade de modelos de negócio inovadores. No entanto, apesar do reconhecimento geral da importância do alinhamento estratégico entre Negócios e TI, as pesquisas sobre a forma como esse alinhamento é alcançado e sustentado ao longo do tempo são insuficientes (Sabherwal \& Chan, 2001).

Inicialmente, os modelos clássicos da literatura identificavam a ocorrência do AE como uma tarefa estática a ser realizada durante parte do processo de planejamento estratégico (diagnóstico de ambiente e formulação de estratégias). A partir do ano 2000, modelos estendidos e complementares vêm sendo desenvolvidos, focando o $\mathrm{AE}$ como um processo contínuo, incremental e constante ao longo de todo o processo de planejamento estratégico (diagnóstico, formulação, implementação e avaliação) e em seus ciclos seguintes. Assim, desde então a maioria dos modelos propostos tem buscado observar as melhores práticas de promoção, o nível de maturidade, os elementos habilitadores e inibidores e a importância da promoção em cada etapa do processo de planejamento estratégico (Brodbeck \& Hoppen, 2003; Luftman, 2000, 2003; Maes, Rijenbrij, Truijens, \& Goedvolk, 2000; Avison et al., 2004).

Uma vez que as áreas de negócio e TI compartilham um entendimento comum do modelo de negócio da organização, refletem em conjunto sobre como os objetivos da estratégia de negócios conduzem as mudanças no modelo de negócios e, consequentemente, nos Sistemas de Informações. Em contrapartida, há também o questionamento sobre como a evolução das TICs (Tecnologias de Informação e Comunicação) direciona mudanças no modelo de negócios e na estratégia das 
organizações. Tais afirmações são uma extensão natural do Modelo de Alinhamento Estratégico proposto por Henderson e Venkatraman (1993), que é definido a partir de quatro domínios fundamentais de escolha estratégica: (a) Estratégia empresarial; (b) Estratégia de tecnologia da informação; (c) Infraestrutura organizacional e processos e; (d) Infraestrutura de tecnologia da informação e processos. Assim, o modelo aborda a adequação estratégica entre a 'estratégia de TI/SI' e a 'estratégia de negócios', bem como a integração funcional entre a 'infraestrutura organizacional e processos' e a 'infraestrutura de TI/SI e processos' (Osterwalder, Pigneru, \& Tucci, 2005).

Osterwalder, Pigneur e Tucci (2005) demonstram como o modelo de negócio (MN) pode servir de ferramenta para conceituar e ilustrar uma estratégia de negócios e seus objetivos, conforme exposto na Figura 1. O MN poderia ser integrado com o modelo da organização (que representa a infraestrutura organizacional e processos) e o modelo de SI (que representa a infraestrutura informacional, aplicações e interfaces de usuário). Assim, segundo os autores citados,

O modelo de negócio é a descrição de valor que uma empresa oferece a um ou vários segmentos de clientes, além da descrição da arquitetura da empresa e sua rede de parceiros para a criação, marketing e entrega deste valor, com a finalidade de gerar fluxos de receitas lucrativas e sustentáveis (Osterwalder, Pigneur, \& Tucci, 2005, p.17).

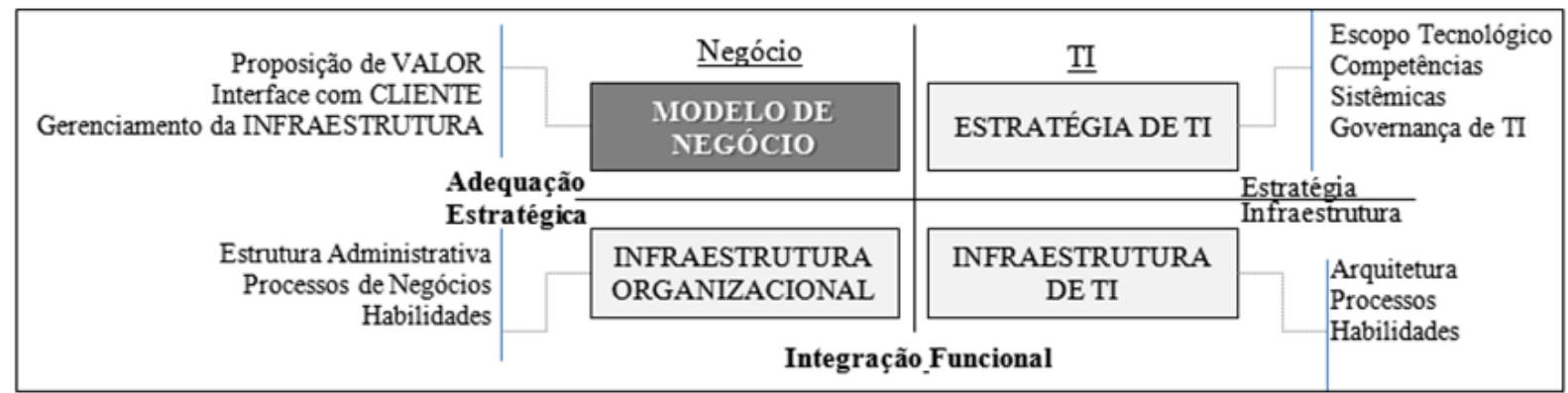

Figura 1

Alinhamento entre negócios e TI/SI.

Fonte: adaptado de Osterwalder, A., Pigneur, Y. \& Tucci, C. L. (2005). Clarifying business models: origns, present and future of the concept. Communications for the Association for Information Systems, 15, May e Pigneur \& Tucci (2005), adaptado de Henderson, J. C. \& Venkatraman, N. (1993). Strategic alignment: leveraging information technology for transforming organizations. IBM Systems Journal, 32(1), 4-16 
Neste moderno mundo digital, em oposição ao ambiente de negócios tradicional, traduzir a estratégia de negócios em processos de negócios tornou-se um importante desafio para as empresas contemporâneas. Há de se ressaltar ainda que os atuais processos de negócios da empresa baseiam-se fundamentalmente em TICs. Além disso, o atual ambiente empresarial é mais dinâmico, caracterizando-se por rápidas mudanças e forte pressão dos stakeholders, além da complexidade da gestão moderna dos negócios cada vez mais dependente da tecnologia.

Por isso, o tema modelo de negócio ganhou proeminência nos últimos anos, ao oferecer uma ferramenta conceitual que, por meio do alinhamento entre a estratégia de negócios e os processos de negócios, incluindo-se aí os sistemas de informação, reduz a lacuna entre ambos e proporciona uma harmonização fundamental entre essas camadas organizacionais (Al-Debei \& Avison, 2010).

Osterwalder, Pigneur e Tucci (2005) identificaram e compararam os blocos constituintes mais comuns na literatura pertinente aos modelos de negócios. Desta análise, nove blocos emergiram: proposta de valor, segmentos de clientes, canal, relacionamento com clientes, atividades-chave, recursos principais, principais parcerias, estrutura de custos e fontes de receita.

\section{Modelo de Luftman (2000)}

O modelo de AE de Luftman (2000) foi inspirado no conceito do Capability Maturity Model (CMM), desenvolvido em 1988 pelo Software Engineering Institute (SEI) da Carnegie Mellon University (Humphre, citado por Sledgianowski, Luftman \& Reilly, 2006).

Este modelo de avaliação do nível de maturidade do alinhamento estratégico (AE) mostra uma abordagem integrada e abrangente para as organizações averiguarem o alinhamento entre os seus negócios e a TI. Em termos operacionais, os critérios são descritos por um conjunto de práticas, permitindo assim que cada variável em particular seja avaliada com o uso de uma escala do tipo Likert de 1 a 5. Ao final da avaliação, obtém-se um escore equivalente ao nível que indica o estágio (de 1 a 5) em que a organização se encontra em relação à maturidade do alinhamento estratégico entre a $\mathrm{Tl}$ e os negócios. O resultado alcançado fornece à organização um roteiro que identifica as oportunidades para melhorar a harmonia de relacionamento entre os negócios e a TI, objetivando a agregação de valor (Luftman, 2000; Rigoni, 2006; Brodbeck, Rigoni, \& Hoppen, 2009). 
A Figura 2 ilustra os níveis de maturidade do AE de uma organização. Assim, quanto maior o gap entre a estratégia de negócio e a estratégia de TI, mais baixo será o nível de maturidade apresentado pela organização.

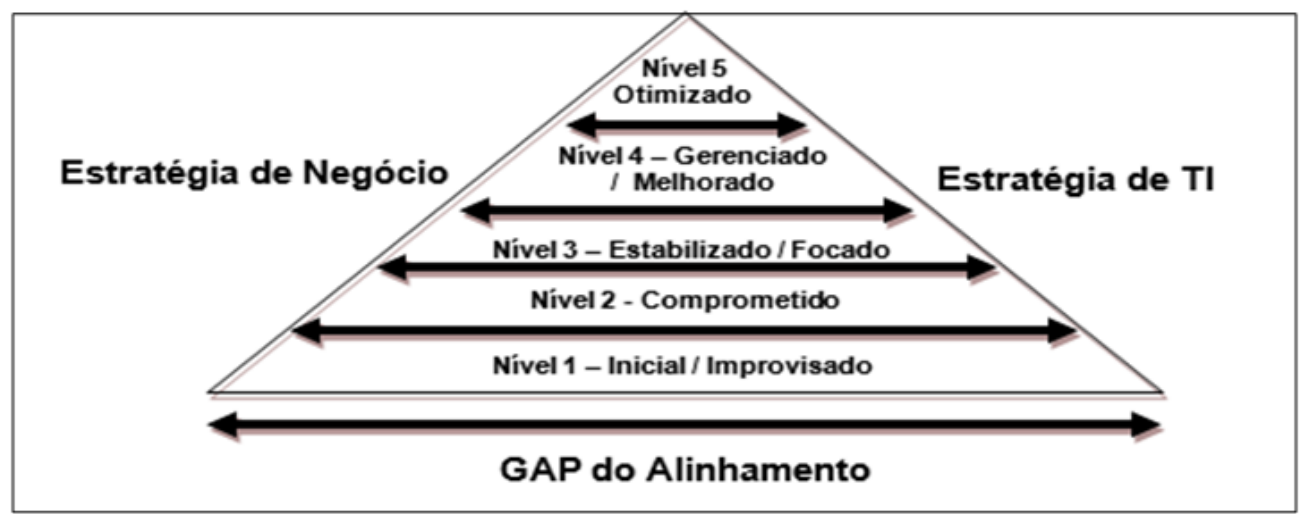

Figura 2

Níveis de maturidade do AE.

Fonte: adaptado de Luftman, J. N. (2003). Assessing business-IT alignment. Information System Management, 20(4), 9-15, Autunn.

Os componentes do modelo de AE propostos por Luftman (2000) são originários do modelo de Henderson \& Venkatraman (1993) em relação aos aspectos estratégia de negócio e estratégia de TI. Porém, o modelo de Luftman (2000) traz incrementos voltados à pesquisa sobre os fatores habilitadores/inibidores do AE de Luftman, Papp e Brier (1999). Assim, os critérios de maturidade agem como facilitadores ou inibidores na obtenção de maior integração entre os objetivos de negócios e de TI (Luftman, Papp \& Brier 1999). Os seis critérios do modelo de maturidade de Luftman (2000) são descritos a seguir:

- Comunicação - Avalia a efetiva troca de ideias, conhecimentos e informações entre as áreas quanto à estratégia da organização, planos, ambientes de TI e do negócio. A palavra-chave é facilitar a interação, compartilhamento de riscos e prioridades na organização;

- Medidas de valor e competência - Verifica se há indicadores que possam demonstrar o valor da TI para os negócios, de modo que os executivos de negócio e de $\mathrm{TI}$ compreendam e aceitem tais indicadores. O nível de serviços deve estar atrelado aos critérios claramente passíveis de 
recompensa (quando excederem as expectativas) ou de penalidade (quando ficarem abaixo das expectativas);

- Governança - Avalia se a autoridade da tomada de decisões de TI está claramente definida; se os gerentes de negócios e de TI discutem para estabelecer prioridades e alocar recursos de TI nos níveis operacionais, táticos e estratégicos da organização;

- Parcerias - Trata da avaliação do relacionamento entre TI e unidades de negócios, avaliando qual o papel que a TI possui na definição das estratégias de negócios, o grau de confiança entre as áreas e como cada parte percebe a contribuição da outra;

- Escopo e arquitetura - Avalia a maturidade da TI ao buscar ir além das atividades de back-office e front-office, assumindo papel de apoio ao negócio e propiciando uma infraestrutura flexível e transparente aos parceiros de negócios e clientes; avaliando e aplicando efetivamente as tecnologias emergentes; facilitando e orientando os processos e estratégias de negócios como padrão verdadeiro, além de prover soluções personalizadas às necessidades dos clientes;

- Habilidades - Avalia as práticas de recursos humanos, tais como contratação, treinamento, salário, feedback de desempenho e oportunidades de carreira, bem como a cultura e o ambiente social da organização.

\subsection{Gerenciamento de projeto, programa e portfólio}

A dimensão estratégica enfatiza a eficácia na geração de vantagens competitivas e inovação das organizações por meio dos projetos (Shenhar \& Dvir, 2010). Para o Project Management Institute, um projeto é "um esforço temporário, empreendido para criar um produto, serviço ou resultado único" (PMI, 2013, p.5). Quanto ao gerenciamento de projeto, o PMl o define como "a aplicação de conhecimentos, habilidades e técnicas às atividades do projeto a fim de atender aos seus requisitos" (PMI, 2013, p. 8). Na visão de Shenhar e Dvir (2010, p. 16) projetos são "os motores que impulsionam inovações de ideias à comercialização. Mas 
projetos também são propulsores que fazem com que as organizações sejam melhores, mais fortes e mais eficientes".

O gerenciamento de projetos como disciplina formal nasceu em meados do século XX. No entanto, seus principais conceitos foram firmados durante a guerra fria ocorrida a partir da década de 1950. Nesta época, o governo americano tomou ações voltadas ao desenvolvimento tecnológico, tais como: a criação da NASA em 1958, o aumento do orçamento da Fundação Nacional de Ciências Americana e a criação do Programa de Mísseis Polaris. O Departamento de Defesa Americano (DOD) tinha urgência para realizar tal programa e as ferramentas de gerenciamento de projetos tradicionais não eram suficientes para garantir a entrega do projeto. Foi então que, juntamente com William Frazar, desenvolveu o PERT (Program Evaluation and Review Technique), um sistema de sequenciamento de atividades que determina o menor tempo para a conclusão de um projeto. A partir de então, a aplicação deste instrumento passou a ser obrigatória nos projetos da marinha americana. A Agência de Pesquisa Avançada de Projetos de Defesa do Pentágono iniciou nos anos 1960 o projeto de uma rede de computadores chamada ARPANET, que foi a percussora da atual Internet (Shenhar \& Dvir, 2010).

A fundação do Project Management Institute (PMI) em 1969 é sintomática para a evolução e a formalização do tema nesse período. Porém, somente a partir da década de 1980 é que os projetos começaram a aparecer e ganharam força no ambiente de negócios. Em 1985, o programa Total Quality Management (TQM Gestão da Qualidade Total) torna-se o primeiro aliado do gerenciamento de projetos (Kerzner, 2006). Segundo Frame (1999, citado por Rabechini Júnior, 2005), sua adoção se intensificou principalmente na década de 1990, sendo mencionada por diversos estudiosos como disciplina obrigatória nas empresas que buscavam desenvolver e manter vantagens competitivas.

O guia de melhores práticas do PMI denominado PMBOK® (Project Management Body of Knowledge) foi desenvolvido inicialmente em 1987 como um white paper (trabalho em preparação). Sua primeira edição oficial foi lançada em 1996. Contando com contribuições voluntárias de acadêmicos e profissionais da temática de projetos, versões posteriores do PMBOK® foram lançadas em 2000, 2004, 2008 e 2013 (PMI, 2013). 
A partir do ano 2000, amplia-se o apoio por parte dos executivos e padrões mundiais de excelência são definidos para a gestão de projetos (Kerzner, 2006). Em função da emergência das fusões e aquisições de empresas de classe mundial, criando-se assim mais empresas multinacionais, a gestão de projetos globais colocase como um grande desafio neste início de milênio. Além disso, modelos e medições do grau de maturidade da gestão de projetos começam a surgir para auxiliar as empresas na aplicação do planejamento estratégico para a gestão de projetos (Ibbs \& Kwak, 2000; Kerzner, 1999; PMI, 2003; Carvalho et al., 2003; Rabechini Júnior, 2005).

No entanto, Kerzner (2006) alerta que as empresas não realizam o planejamento estratégico para a gestão de projetos com o mesmo cuidado e precisão que realizam o planejamento estratégico para novos produtos e serviços. Além disso, o autor argumenta ainda que o planejamento estratégico para a gestão de projetos difere de outras formas de planejamento por ser mais frequentemente realizado no nível administrativo intermediário, em vez de ser efetivado no nível executivo.

Para Shenhar (2004), o gerenciamento de projetos não deve apenas buscar cumprir cronogramas, metas orçamentárias e atender requisitos. É preciso ir além, uma vez que o gerenciamento de projetos deve estar alinhado às estratégias da organização ao nível tático (SHENHAR, 2004).

Em 2008, o PMI lança a quarta edição do $\mathrm{PMBOK}{ }^{\circledR}$. O padrão estabelecido nesta edição, exclusivo ao campo de gerenciamento de projetos, apresenta relacionamento com outras disciplinas, tais como gerenciamento de programas e gerenciamento de portfólios. Já no início de 2013, a quinta edição do PMBOK® é lançada, denotando a constante evolução desta área do conhecimento.

Segundo pesquisa realizada pela Pmsurvey (2011), a principal área a utilizar as metodologias de gerenciamento de projetos nas empresas é a área de $\mathrm{Tl}$, com $67,3 \%$ das indicações. Na sequência, a área de Engenharia aparece com $41,4 \%$ e a área de Produção/operação com 33,7\%. Um bom indicador do crescimento desta disciplina junto às áreas e profissionais das empresas é expresso pelo número de gerentes de projetos certificados pelo PMI®. A credencial PMP® (Project Management Professional) é o título mais reconhecido no mercado de gerenciamento de projetos (PMI, 2012). No mundo, até o abril/2012, contabilizava-se 477.031 PMPs em 185 países credenciados (PMI, 2012). 
Em organizações maduras, o gerenciamento de projetos existe num contexto mais amplo, orquestrado pelo gerenciamento de programas e gerenciamento de portfólios, também conhecido por PPM (Project Management Portfolio).

Segundo o PMI (2013, p. 9), "um programa é definido como um grupo de projetos relacionados, gerenciados de modo coordenado para a obtenção de benefícios e controle que não estariam disponíveis se eles fossem gerenciados individualmente", ou seja, um projeto não precisa fazer parte de um programa, mas um programa sempre conterá projetos (PMI, 2013). Em complemento, "um portfólio refere-se a um conjunto de projetos ou programas, agrupados para facilitar o gerenciamento eficaz a fim de atingir os objetivos estratégicos de negócios" (PMI, 2013 , p. 8). Os projetos ou programas do portfólio não necessariamente devem estar diretamente relacionados. O gerenciamento de portfólio concentra-se em um nível mais agregado, envolvendo a identificação, seleção, financiamento, priorização, autorização e combinação apropriada de projetos, programas e iniciativas que visam atingir metas e objetivos estratégicos de negócios (PMI, 2013).

Os comitês de análises de portfólios são geralmente constituídos por executivos da organização que atuam com um painel de seleção de projetos. Eles analisam cada projeto de acordo com o retorno sobre o investimento, o seu valor e os riscos associados à adoção do projeto, além de outros atributos (PMl, 2013). O planejamento estratégico e a seleção estratégica de projetos são semelhantes no que se refere às implicações quanto ao lucro e ao crescimento da organização (Kerzner, 2006).

No entanto, Tarafdar e Qrunfleh (2010) alertam para a necessidade de evitar o excesso de formalização no gerenciamento de portfólios e priorização de projetos. Além disso, os autores argumentam que parte do orçamento da TI deveria ficar sem alocação para eventuais emergências, uma vez que projetos não planejados surgem e se tornam de alta prioridade, mesmo sem terem orçamento aprovado para o ano em questão.

Blichfeldt \& Eskerod (2008) ressaltam que esses projetos de pequena escala (extraoficiais) são executados sem o conhecimento da alta administração e consomem os recursos de projetos aprovados pelo PPM. Os autores sugerem que o gerenciamento de portfólio deveria abranger todos os projetos, sem exceção. Porém, concordam com a argumentação de Tarafdar e Qrunfleh (2010) quanto a uma 
reserva de recursos, ao sugerirem a criação de um pulmão de recursos controlado de forma flexível. Dessa forma, seria possível executar os projetos extraoficiais sem desvio de recursos dos projetos oficiais do portfólio.

\subsection{A estrutura organizacional e o escritório de projetos}

A estrutura organizacional é um fator ambiental da empresa que pode afetar a disponibilidade dos recursos e influenciar a maneira como os projetos são conduzidos. As estruturas organizacionais variam de funcionais às orientadas a projetos, com diversas estruturas matriciais ou híbridas entre estes extremos (kerzner, 2006; PMI, 2013).

Historicamente, a gestão de projetos era praticada apenas nos setores da indústria fortemente orientados a projetos (por exemplo: setor aeroespacial, construção civil), nos quais o gerente de projetos tinha a responsabilidade pelos lucros e perdas, sendo assim formalizada a profissão de gestor de projetos. Nos setores de mercado não orientados a projetos, a sobrevivência dependia de produtos ou serviços, jamais de um fluxo continuado de projetos. A lucratividade era identificada pelas funções de marketing e vendas, sendo a função de gerente de projetos dificilmente vista como profissão (Kerzner, 2006).

A administração moderna foi forçada a concluir que poderia comandar a empresa com base na 'gestão por projeto' e concretizar os benefícios de ambos os tipos de organização (orientada a projetos e tradicional). A aceitação e o crescimento da gestão de projetos nos últimos anos tiveram como principais patrocinadores os setores híbridos. As mudanças mais rápidas são, provavelmente, as relacionadas às empresas do setor bancário, farmacêutico, petróleo e gás e ainda telecomunicações (Kerzner, 2006).

Outro aspecto a ser considerado volta-se à cultura organizacional, estilo e estrutura da organização, que influenciam na maneira como os projetos são priorizados, planejados e executados (Kerzner, 2006). Na organização funcional, a hierarquia clássica apregoa que cada funcionário possui um superior bem definido. Além disso, cada departamento fará seu trabalho do projeto de modo independente dos outros departamentos (PMI, 2013). Já as organizações matriciais caracterizamse por serem uma combinação de características das organizações funcionais e das organizações orientadas a projetos simultaneamente. Tais organizações podem ser 
classificadas em matriciais fracas, balanceadas e fortes. As matriciais fracas mantêm muitas das características de uma organização funcional, sendo o papel do gestor de projetos mais parecido com o papel desempenhado por um coordenador ou facilitador. Já as organizações matriciais fortes possuem muitas das características da organização orientada a projetos, contemplando um gestor de projetos que trabalhe em tempo integral com autoridade considerável e pessoal administrativo próprio. Por fim, a organização matricial balanceada reconhece a necessidade do gestor de projetos, porém não fornece autoridade total para este profissional sobre o projeto e sobre o seu financiamento (PMI, 2013).

$\mathrm{Na}$ estrutura organizacional orientada a projetos, os projetos são predominantemente estratégicos para a organização. Entretanto, pesquisas de 2011 com 754 empresas do Brasil revelaram que somente $23 \%$ possuem estrutura organizacional orientada a projetos (orientada a projetos ou clientes) e $10 \%$ possuem uma estrutura matricial forte, na qual os gerentes de projetos têm mais influência que os gerentes departamentais. A maior parte das organizações concentra-se na estrutura funcional ou departamentalizada (39\%) e na estrutura matricial balanceada (29\%) (Pmsurvey, 2011).

É importante destacar o papel do PMO (Project Management Office) ou escritório de projetos, principalmente em uma estrutura orientada a projetos. O PMO pode ser definido como uma estrutura organizacional estabelecida para apoiar os gerentes e as equipes de projetos na implementação de práticas, metodologias, ferramentas e técnicas para o gerenciamento de projetos (Dai \& Wells, 2004). O escritório de projetos tem como responsabilidade manter toda a propriedade intelectual relativa à gestão de projetos. Além disso, deve ainda sustentar ativamente o planejamento estratégico (Kerzner, 2006).

O PMO pode oferecer, mas não se limita a: a) serviços de suporte administrativo, como políticas, metodologias e modelos; b) treinamento, aconselhamento e orientação de gestores de projetos; c) suporte, orientação e treinamento em relação a como gerenciar projetos e utilizar as ferramentas; d) alinhamento dos recursos humanos dos projetos; e) comunicação centralizada entre gestores de projetos, patrocinadores, gestores de negócio e outros stakeholders (PMI, 2013; Kerzner, 2006). 
Face ao contexto exposto na seção de Introdução, bem como o Referencial Teórico apresentado, a presente pesquisa estabelece as seguintes hipóteses a serem testadas no levantamento de campo:

H01 - O escritório de projetos (PMO) - responsável pelos processos de gestão de projetos de $\mathrm{TI}$ - não influencia no alinhamento dos projetos de $\mathrm{TI}$ aos modelos de negócio das organizações.

H02 - A estrutura organizacional orientada a projetos não influencia no alinhamento dos projetos de $\mathrm{TI}$ aos modelos de negócio das organizações.

\section{$3 \quad$ Metodologia da pesquisa}

A presente pesquisa classifica-se como exploratória-descritiva de natureza quantitativa, com utilização do método de levantamento de campo (survey). Segundo Gil (2010), a pesquisa exploratória tem como objetivo proporcionar maior familiaridade com o problema, com vistas a torná-lo mais explícito ou a construir hipóteses.

O universo desta pesquisa é formado por organizações de diversos setores de atuação no Brasil. O sujeito da pesquisa é o profissional que atua em projetos de Tecnologia da Informação (TI), representantes da área de tecnologia e de negócios. Obtiveram-se 327 questionários válidos de ClOs, gerentes de projetos, gerentes de programas, gerentes de departamentos, coordenadores, analistas e consultores, dentre outros.

O procedimento de amostragem adotado foi por conveniência, complementado com o método bola-de-neve, ao ser solicitado ao respondente escolhido que indicasse outros profissionais com perfil semelhante para participar da pesquisa, gerando assim uma amostra não probabilística. Neste tipo de procedimento, "o pesquisador usa métodos subjetivos, tais como sua experiência pessoal, conveniência e conhecimento especializado para selecionar os elementos da amostra" (Hair, Babin, Money, \& Samouel, 2005, p. 246).

A Tabela 1 expõe as principais questões que compõem o bloco 'caracterização da organização' do instrumento de pesquisa aplicado. 
Tabela 1

Variáveis de caracterização da organização do instrumento de pesquisa

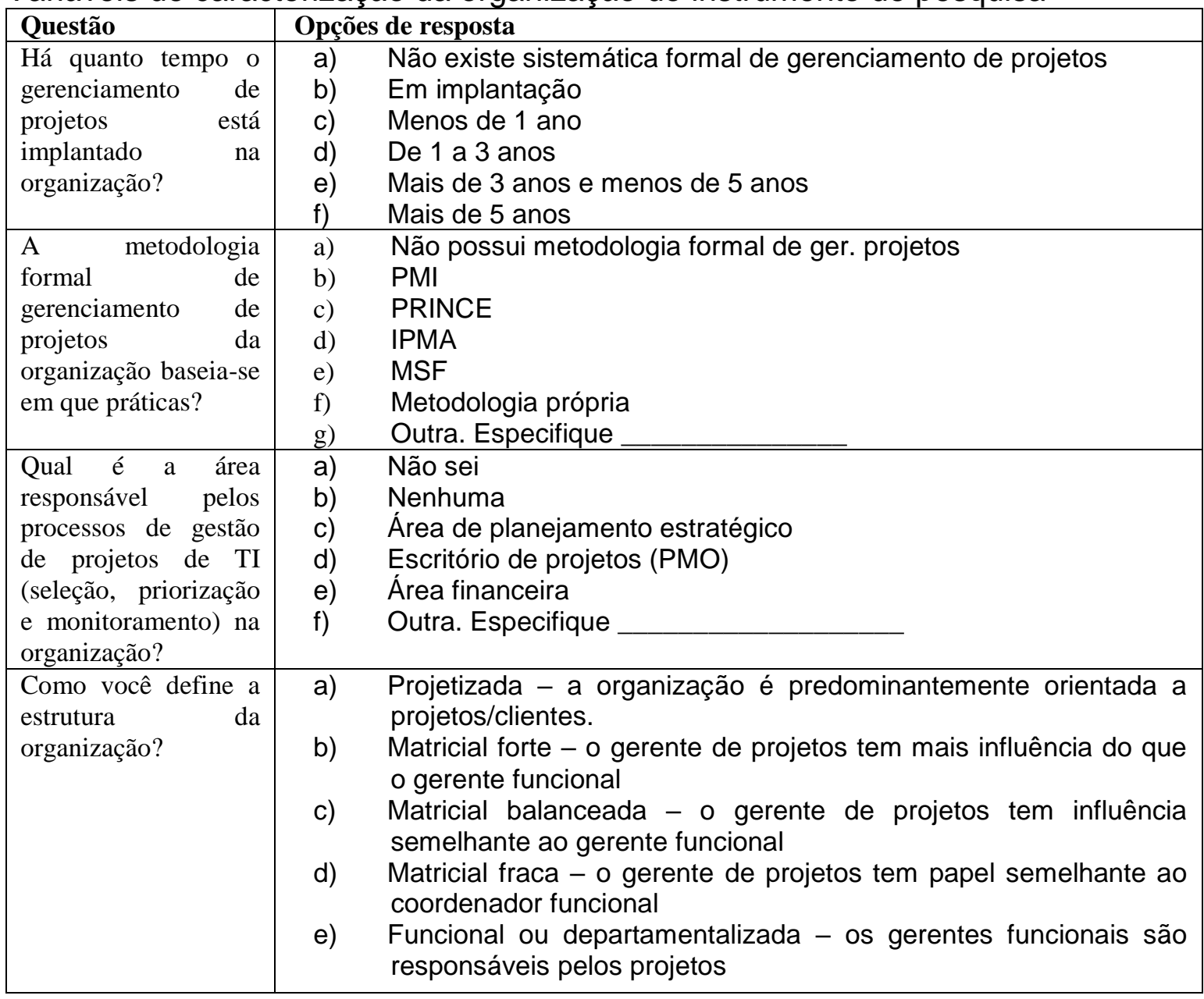

Fonte: elaborado pelos autores.

O instrumento de pesquisa foi estruturado a partir de 26 práticas (variáveis) do alinhamento estratégico (AE) baseadas no modelo proposto por Lufman (2000), que constituem os constructos: a) Comunicação, b) Medidas de Valor e Competência, c) Governança, d) Parcerias, e) Escopo e Arquitetura e f) Habilidades. As variáveis de cada constructo são apresentadas na Tabela 2. 


\section{Tabela 2}

Variáveis de alinhamento estratégico do instrumento da pesquisa

\begin{tabular}{|c|c|c|}
\hline & Variável & Constructo: Comunicação \\
\hline & COM_1 & Entendimento do negócio pela área de TI. \\
\hline & COM_2 & Entendimento dos conceitos básicos de TI pela área de negócios \\
\hline & COM_3 & Relacionamento entre as áreas de TI e negócios \\
\hline & COM_4 & Endereçamento das informações do projeto \\
\hline & COM_5 & Efetividade na comunicação \\
\hline & Construct & Medidas de Valor e Competência \\
\hline & VAL_1 & Cronograma \\
\hline & VAL_2 & Requisitos de negócios \\
\hline & VAL_3 & Orçamento \\
\hline & $\mathrm{VAL} 44$ & Impacto comercial e ganhos econômicos \\
\hline 됙 & $\mathrm{VAL} 5$ & Sucesso em projetos \\
\hline 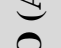 & Construct & Governança \\
\hline 8 & GOV_1 & Projetos de TI e estratégias de negócios \\
\hline$\Xi$ & GOV_2 & Seleção e priorização dos projetos \\
\hline 空 & GOV_3 & Papeis e responsabilidades \\
\hline$\underline{a}$ & GOV_4 & Autonomia do gerente de projetos \\
\hline 里 & Construct & Parcerias \\
\hline 牙 & PAR_1 & Reconhecimento do valor agregado dos projetos de TI \\
\hline$=$ & PAR_2 & Compartilhamento de riscos e recompensas \\
\hline$Z_{\square}$ & PAR_3 & Apoio e participação da área de negócios \\
\hline$\sum$ & PAR_4 & Senso de urgência e esforços por parte da TI \\
\hline$\$$ & Construct & Escopo e Arquitetura \\
\hline$\overline{\mathbf{Z}}$ & ESC_1 & Soluções personalizadas e tecnologias emergentes \\
\hline 马 & ESC_2 & Documentação e conformidade da arquitetura de TI \\
\hline$\ll$ & ESC_3 & Flexibilidade e transparência da arquitetura de TI \\
\hline 8 & Construct & Habilidades \\
\hline $\overrightarrow{2}$ & HAB_1 & Inovação e empreendedorismo \\
\hline$\circlearrowright$ & HAB_2 & Conhecimento do gerente do projeto no negócio \\
\hline$\underline{\underline{E}}$ & HAB_3 & Capacidade do gestor de projetos de integração da equipe e mediação de conflitos \\
\hline 迹 & $\begin{array}{l}\mathrm{HAB} \_4 \\
\mathrm{HAB} 5\end{array}$ & $\begin{array}{l}\text { Treinamento } \\
\text { Retenção de profissionais e valorização de conhecimentos }\end{array}$ \\
\hline
\end{tabular}

Fonte: elaborado pelos autores.

Para obter o escore de maturidade do $A E$, apurou-se a média das pontuações do conjunto de variáveis de cada constructo, obtendo-se assim um escore por constructo (critério) e um escore geral obtido pela média das pontuações dos seis constructos do modelo de Luftman (2000): Comunicação, Medidas de Valor e Competência, Governança, Parcerias, Escopo e Arquitetura, e Habilidades.

Com auxílio do software estatístico SPSS, optou-se por realizar a CATPCA (Categorical Principal Components Analysis) intra-bloco, utilizando-se a regra eigenvalue acima de ' 1 ' juntamente com o coeficiente a (alpha) de Cronbach. Tal expediente teve a finalidade de verificar se as práticas constituintes dos fatores estão associadas entre si e se representam um conceito único, garantindo-se assim a unidimensionalidade (Hair Jr. et al., 2006). Para estudos exploratórios, Hair Jr., Anderson \& Tatham (2006) sugerem que sejam aceitáveis conjuntos de dados com $\alpha$ (alpha) de Cronbach acima de 0,60. 
Utilizou-se uma escala ordinal, ou seja, não métrica. Com objetivo de investigar com que frequência tais práticas de $A E$ são realizadas na organização, uma escala tipo Likert foi utilizada (1 - Nunca, 2 - Raramente, 3 - Às vezes, 4 Frequentemente e 5 -Sempre). A mediana é a medida de tendência central mais apropriada para lidar com a escala ordinal (Hair Jr. et al., 2005; Malhotra, 2006). Para as hipóteses instituídas nesta pesquisa utilizou-se o teste não paramétrico de Mann-Whitney, apropriado para comparar duas amostras independentes (Malhotra, 2006). Além disso, a mediana foi selecionada para ser o critério de avaliação aplicado.

\section{Apresentação e análise dos resultados}

Em relação ao perfil dos 327 respondentes, observou-se maior incidência de profissionais do sexo masculino (73,7\%). Quanto à idade dos respondentes, observou-se forte incidência na faixa etária entre 31 e 50 anos $(74,3 \%)$, o que é condizente com a alta escolaridade, uma vez que $69,1 \%$ dos respondentes relataram possuir pós-graduação completa. Entre os respondentes, 64,5\% declararam possuir função de gestão. Grande parte dos respondentes pertence à área de $\mathrm{TI}(73,4 \%)$, fato consistente com o que se observa nas organizações. Ou seja, encontra-se no staff de projetos de TI um número maior de integrantes da própria $\mathrm{TI}$ e um número menor de integrantes de outras áreas de negócio/administrativa da organização.

A Tabela 3 demonstra a opinião dos respondentes quanto à existência formal de um processo que defina as diretrizes/melhores práticas em gestão de projetos na organização.

\section{Tabela 3}

Implantação da sistemática de gerenciamento de projetos

\begin{tabular}{lll}
\hline & Frequência & $\%$ \\
\hline Não existe sistemática formal & 33 & 10,1 \\
Em implantação & 20 & 6,1 \\
Existe, há menos de 1 ano & 6 & 1,8 \\
Existe, de 1 a 3 anos & 42 & 12,8 \\
Existe, há + de 3 e - de 5 anos & 38 & 11,6 \\
Existe há 5 anos ou mais & 188 & 57,5 \\
\hline Total & 327 & 100,0 \\
\hline
\end{tabular}

Fonte: elaborado pelos autores. 
A Tabela 4 expõe as informações da área responsável pelas atividades de seleção, priorização e monitoramento dos projetos de tecnologia da informação.

\section{Tabela 4}

Área responsável pelos projetos de TI

\begin{tabular}{lll} 
& Frequência & $\%$ \\
\hline Escritório de projetos (PMO) & 172 & 52,6 \\
Diretoria & 46 & 14,1 \\
Área de Planejamento estratégico & 30 & 9,2 \\
Área de TI & 20 & 6,1 \\
Não sei & 15 & 4,6 \\
Nenhuma & 8 & 2,4 \\
Outras & 3 & 0,9 \\
Não informado & 33 & 10,1 \\
\hline Total & 327 & 100,0 \\
\hline
\end{tabular}

Fonte: elaborado pelos autores.

A estrutura organizacional classificada pelos respondentes é descrita na Tabela 5.

\section{Tabela 5}

Estrutura organizacional

\begin{tabular}{lll}
\hline & Frequência & $\%$ \\
\hline Orientada a projetos & 79 & 24,2 \\
Matricial forte & 21 & 6,4 \\
Matricial balanceada & 66 & 20,2 \\
Matricial fraca & 70 & 21,4 \\
Funcional ou departamentalizada & 91 & 27,8 \\
\hline Total & 327 & 100,0 \\
\hline
\end{tabular}

Fonte: elaborado pelos autores.

A utilização de melhores práticas em gestão de projetos adotadas pelas organizações é exposta na Tabela 6.

Tabela 6

Práticas utilizadas na metodologia de gerenciamento de projetos

\begin{tabular}{lll}
\hline & Frequên & $\%$ \\
\hline PMI & 196 & 59,9 \\
Metodologia própria & 77 & 23,5 \\
Prince & 2 & 0,70 \\
IPMA & 1 & 0,30 \\
\hline Total & 327 & 100,0 \\
\hline
\end{tabular}

Fonte: elaborado pelos autores.

\subsection{Verificação das hipóteses}

Nesta seção, as hipóteses previamente estabelecidas são testadas, visando assim explicar certos fatos ou fenômenos (Hair Jr. et al., 2005). Os pesquisadores em administração geralmente consideram $<0,05$ ou $<0,01$ como nível aceitável de 
significância (Hair Jr. et al., 2005). Para este estudo considerou-se $\alpha=0,05$ como nível de significância.

\subsubsection{Hipótese $H_{01}$}

A hipótese H01, conforme definida anteriormente, apresenta a seguinte afirmação:

H01 - O escritório de projetos (PMO), sendo a área responsável pelos processos de gestão de projetos de $\mathrm{TI}$, não influencia na maturidade do alinhamento dos projetos de $\mathrm{TI}$ ao modelo de negócio da organização.

\section{Tabela 7}

Mediana por constructo - PMO x Outras áreas

\begin{tabular}{|c|c|c|c|c|c|c|c|c|c|c|}
\hline \multirow[t]{2}{*}{ Área } & \multicolumn{7}{|c|}{ Mediana por constructo } & \multirow[b]{2}{*}{$\begin{array}{l}\text { Media- } \\
\text { na } \\
\text { Geral }\end{array}$} & \multirow[b]{2}{*}{$\mathbf{N}$} & \multirow[b]{2}{*}{$\begin{array}{l}\text { Posto } \\
\text { médio }\end{array}$} \\
\hline & $\mathbf{a}^{*}$ & $\mathbf{b}^{*}$ & $\mathbf{c}^{*}$ & $d^{*}$ & $\mathbf{e}^{*}$ & $\mathbf{f}^{*}$ & $g^{*}$ & & & \\
\hline PMO & 4,00 & 4,00 & 4,00 & 3,50 & 4,00 & 3,50 & 3,00 & 4,00 & 173 & 157,05 \\
\hline Outras & 4,00 & 3,50 & 3,50 & 3,50 & 3,00 & 3,00 & 3,00 & 3,00 & 124 & 137,77 \\
\hline Total & 4,00 & 4,00 & 4,00 & 3,50 & 4,00 & 3,50 & 3,00 & 4,00 & 297 & \\
\hline
\end{tabular}

Fonte: elaborado pelos autores.

Nota: * a=Comunicação, $b=$ Medidas de valor e competência, $c=$ Governança, $d=P$ arcerias, $\mathrm{e}=$ Escopo e arquitetura, $\mathrm{f}=$ Habilidades, $\mathrm{g}=$ Modelo de negócio.

$\mathrm{Na}$ Tabela 7 nota-se que o Escritório de Projetos (PMO) apresenta maiores medianas nas práticas dos constructos 'b' (medidas de valor e competência), 'c' (governança), 'e' (escopo e arquitetura) e ' $f$ ' (habilidades) em relação às demais áreas.

\section{Tabela 8}

Teste estatístico - PMO

\begin{tabular}{lc}
\hline Teste * & Mediana \\
\hline Mann-Whitney U & 9333,000 \\
Wilcoxon W & 17083,000 \\
$Z$ & $-2,095$ \\
Asymp. Sig. (2-tailed) & $\mathbf{0 , 0 3 6}$ \\
\hline Fonte: elaborado pelos autores. \\
Nota: * Grouping Variable: PMO
\end{tabular}

Ao observar a Tabela 8, verifica-se que existe diferença estatística significativa (Asymp. Sig. < 0,05) entre o PMO e as demais áreas. Portanto, há evidências para 
rejeitar a hipótese nula $\mathrm{H} 01$, ou seja, o PMO influencia positivamente na maturidade do alinhamento dos projetos de $\mathrm{TI}$ ao modelo de negócio da organização. Vale destacar que a Tabela 4, exposta anteriormente, apresenta o resultado detalhado obtido na pesquisa quanto à área responsável pelos processos de gestão de projetos de TI.

\subsubsection{Hipótese $\mathrm{H}_{02}$}

A hipótese H02, conforme definida anteriormente, apresenta a seguinte afirmação:

H02 - A estrutura organizacional 'projetizada' não influencia na maturidade do alinhamento dos projetos de $\mathrm{Tl}$ ao modelo de negócio da organização.

\section{Tabela 9}

Mediana por constructo - Estrutura 'projetizada' x Outras

\begin{tabular}{|c|c|c|c|c|c|c|c|c|c|c|}
\hline \multirow[t]{2}{*}{ Estrutura } & \multicolumn{10}{|c|}{ Mediana por constructo } \\
\hline & $\mathbf{a}^{*}$ & $\mathbf{b}^{*}$ & $\mathbf{c}^{*}$ & $d^{*}$ & $\mathbf{e}^{*}$ & $\mathbf{f}^{*}$ & $\mathbf{g}^{*}$ & $\begin{array}{l}\text { Mediana } \\
\text { Geral }\end{array}$ & $\mathbf{N}$ & $\begin{array}{l}\text { Posto } \\
\text { médio }\end{array}$ \\
\hline Projetizada & 4,00 & 4,00 & 4,00 & 4,00 & 4,00 & 4,00 & 4,00 & 4,00 & 79 & 199,68 \\
\hline Outras & 4,00 & 3,00 & 3,50 & 3,50 & 3,00 & 3,00 & 3,00 & 3,00 & 248 & 152,63 \\
\hline Total & 4,00 & 3,00 & 4,00 & 3,50 & 4,00 & 3,00 & 3,00 & 4,00 & 327 & \\
\hline
\end{tabular}

Fonte: Elaborado pelos autores.

Nota:* a=Comunicação, b=Medidas de valor e competência, $c=$ Governança, $d=P$ arcerias, e=Escopo e arquitetura, $\mathrm{f}=$ Habilidades, $\mathrm{g}=$ Modelo de negócio.

Observa-se na Tabela 9 que a estrutura da organização 'projetizada' apresenta maiores medianas, contribuindo assim para um maior nível de maturidade em todos os constructos da pesquisa, com exceção do constructo 'a' (comunicação) para o qual não houve diferença.

\section{Tabela 10}

Teste estatístico - Estrutura Projetizada

\begin{tabular}{ll}
\hline Teste * & Mediana \\
\hline Mann-Whitney U & 6977,000 \\
Wilcoxon W & 37853,000 \\
Z & $-4,192$ \\
Asymp. Sig. (2-tailed) & $\mathbf{0 , 0 0 0}$ \\
\hline Fonte: Elaborado pelos autores. \\
Nota: * Grouping Variable: Estrutura organizacional
\end{tabular}


$O$ teste de Mann-Whitney exposto na Tabela 10 demonstrou diferença significativa (Asymp. Sig < 0,05) na comparação da estrutura 'projetizada' com as demais.

Diante disto, há evidência para rejeitar a hipótese nula $\mathrm{H} 02$, ou seja, a estrutura organizacional 'projetizada' influencia positivamente na maturidade do alinhamento dos projetos de TI ao modelo de negócio da organização. Há de se indicar que o resultado detalhado obtido quanto à estrutura organizacional das organizações pode ser observado na Tabela 5.

\section{Considerações finais}

O tema gerenciamento de projetos em sua aplicação aos requisitos específicos de TI ainda está em amadurecimento. No entanto, a área de TI destaca-se como grande fomentadora da evolução desta disciplina. Os dados da pesquisa demonstram que apenas $10,01 \%$ dos respondentes afirmaram não haver em suas organizações uma sistemática formal de gerenciamento de projetos de TI. Ou seja, afirmaram não haver procedimentos documentados das fases e das práticas a serem seguidas. Em contraponto, $57,5 \%$ dos sujeitos pesquisados afirmaram que tal sistemática existe há mais de cinco anos em sua organização, sendo que os demais citaram que tal sistemática está em implantação ou já em exercício há pelo menos um ano.

Do guia de melhores práticas de gerenciamento de projetos do mercado, destaca-se o PMBOK® (Project Management Body of Knowledge) do PMI (Project Management Institute). Além do PMI, vale citar também o IPMA (International Project Management Association), que congrega países europeus, o PRINCE2® (Projects In Controlled Environments) lançado inicialmente como um método para gerenciamento de projetos pelo governo britânico e o AIPM (Australian International Project Management), que representa a Austrália e países vizinhos (Rabechini Júnior, 2005).

Um bom indicador do crescimento do uso das práticas de gestão de projetos é a quantidade de PMP's (Project Management Professional), ou seja, profissionais certificados em gerenciamento de projetos pelo renomado instituto PMI. A credencial $\mathrm{PMP} \circledast$ é frequentemente exigida aos gestores de projetos de TI. Conclui-se que a 
formalização de uma sistemática de gestão de projetos de TI é um processo em solidificação crescente nas organizações contemporâneas.

Pesquisas anteriores já demonstraram que as empresas têm investido na criação e ampliação dos escritórios de projetos ou PMOs (Project Management Office). Além do PMO corporativo, também se observa a existência de PMOs segregados por área nas organizações, sendo que a área de TI lidera este ranking. A área de TI também é apontada como a área prioritária nas organizações quanto à utilização de metodologias de gerenciamento de projetos, seguida por outras áreas tais como Engenharia e Produção/Operação. Uma possível explicação para este fenômeno pode estar voltada ao uso estratégico da tecnologia da informação no alinhamento e direcionamento dos modelos de negócio das empresas, necessitando, assim, de um maior monitoramento e controle desses projetos em específico.

$\mathrm{Na}$ presente pesquisa, o escritório de projetos foi indicado por $52,6 \%$ dos respondentes como sendo a área responsável pela seleção, priorização e monitoramento dos projetos de $\mathrm{TI}$, corroborando dados de pesquisas anteriores expostos no referencial teórico deste trabalho.

Ainda que restrito à amostra deste estudo, a análise da hipótese $\mathrm{H} 01$ mostrou evidências que o PMO influencia positivamente na maturidade do alinhamento dos projetos de $\mathrm{Tl}$ aos modelos de negócio.

A estrutura organizacional é um fator ambiental da empresa que pode afetar a disponibilidade dos recursos e influenciar a maneira como os projetos são conduzidos. Os dados desta pesquisa apresentaram distribuição uniforme quanto às estruturas organizacionais analisadas. No topo do ranking, a estrutura funcional ou departamentalizada se destacou na opinião de $27,8 \%$ dos respondentes, seguida da estrutura orientada a projetos $(24,2 \%)$. Embora bem distintas, ambas as estruturas totalizaram $52 \%$ das respostas dos sujeitos analisados.

Os resultados desta pesquisa corroboram a pesquisa realizada pelo $\mathrm{PMI}$ em 2011 junto a 754 empresas atuantes no Brasil, que revelou que somente $23 \%$ possuem estrutura organizacional orientada a projetos (ou a clientes) e $10 \%$ possuem uma estrutura matricial forte, na qual os gerentes de projetos têm mais influência que os gerentes departamentais. A maior parte das organizações (39\%) ainda se concentra na estrutura funcional, sendo que $29 \%$ configuram-se em estrutura matricial balanceada (Pmsurvey, 2011). 
Vale ressaltar o resultado da análise da hipótese $\mathrm{H} 02$, ainda que considerada a limitação quanto à amostra empregada nesta pesquisa. Os resultados auferidos na pesquisa de campo demonstraram evidências de que a estrutura orientada a projetos influencia positivamente na maturidade do alinhamento dos projetos de $\mathrm{TI}$ aos modelos de negócio das organizações.

Em suma, o presente estudo traz como contribuições a evidenciação da influência positiva exercida pelos escritórios de projetos (PMO) e da estrutura organizacional orientada a projetos para a promoção do alinhamento dos projetos de TI aos modelos de negócio das organizações.

Algumas limitações da presente pesquisa são expostas com a finalidade de auxiliar a correta interpretação dos resultados obtidos. Considerando que este levantamento de campo fez uso de uma amostra por conveniência, ou seja, não probabilística, os resultados ora alcançados não podem ser estendidos a todas as empresas. Trata-se de um estudo exploratório, cuja finalidade é gerar maior conhecimento sobre temas ainda pouco pesquisados. Assim, a presente pesquisa buscou uma evolução na teoria da temática em pauta neste estudo, no entanto, sem esgotar 0 assunto. Ressalta-se também uma limitação natural dos estudos descritivos de recorte transversal, nos quais os dados coletados retratam a realidade num determinado período de tempo.

Para pesquisas futuras recomenda-se, quanto à teoria, buscar novos estudos extensivos aos temas abordados ou ainda voltados a temas adjacentes. Já quanto à pesquisa empírica, além da seleção do perfil dos respondentes, sugere-se que as características das empresas sejam consideradas, tais como: setor de atuação da empresa; b) origem do capital (nacional ou estrangeiro) e, por fim; c) localização das unidades de negócio, visando investigar se há influência da cultura geográfica.

\section{Referências}

Al-Debei, M. M., \& Avison, D. (2010). Developing a unified framework of the business model concept. European Journal of Information Systems, 19, 359-76.

Almeida, L.M., \& Santos, E. M. (2015). Análise da promoção das práticas do alinhamento estratégico entre negócio e tecnologia da informação: um estudo de caso em organização de serviços. Revista Gestão.Org, 13(ed. Especial), 187-99. 
Avison, D., Jones, J., Powell, P., \& Wilson, D. (2004). Using and validating the strategic alignment model. The Journal of Strategic Information Systems, 13(3), 223-46, Aug.

Blichfeldt, B. S., \& Eskerod, P. (2008). Project portfolio management - There's more to it than what management enacts. International Journal of Project Management, 26, 357-65.

Brodbeck, A. F., Rigoni, E. H., \& Hoppen, N. (2009). Strategic alignment maturity between business and information technology in Southern Brazil. Journal of Global Information Technology Management, 12(2), 5-32.

Brodbeck, A., \& Hoppen N. (2003). Alinhamento estratégico entre os planos de negócio e de tecnologia de informação: um modelo operacional para implementação. Revista de Administração Contemporânea, 7(3), 9-33, jul./set.

Carvalho, M. M., Laurindo, F. J. B., \& Pessôa, M. S. P. (2003). Information technology project management to achieve efficiency in brazilian companies. In S. Kamel (Org.). Managing globally with information technology. Hershey: Idea Group, 260-71.

Dai, C. X., \& Wells, W. G. (2004). An exploration of project management office features and their relationship to project performance. International Journal of Project Management, 22, 523-32.

Freitas, A. S. de., Ferreira, L. F. F., Coutinho, F. D., \& Irigaray, H. A. R. (2013). Alinhamento estratégico de tecnologia da informação: o caso da Arcelormittal Tubarão. Revista Eletrônica de Estratégia \& Negócios, 6(3), 3-26, set./dez.

Gil, A. C. (2010). Como elaborar projetos de pesquisa. (5a ed.). São Paulo, Atlas.

Hair Jr., J. F., Babin, B., Money, A. H., \& Samouel, P. (2005). Métodos de pesquisa em administração. Porto Alegre, Bookman.

Hair Jr., J. F., Anderson, R. E., \& Tatham, R. L. (2006). Análise multivariada de dados. (5a ed.). Porto Alegre, Bookman.

Henderson, J. C., \& Venkatraman, N. (1993). Strategic alignment: leveraging information technology for transforming organizations. IBM Systems Journal, 32(1), 4-16.

Ibbs, C. W., \& Kwak, Y. H. (2000). Assessing project management maturity. Project Management Journal, 3(1), 32-43.

Kerzner, H. (1999). Strategic planning for project management using a project management maturity model. New York, John Wiley \& Sons.

Kerzner, H. (2006). Gestão de projetos: as melhores práticas. (2a ed.). Porto Alegre, Bookman. 
Luftman, J. N., Papp, R., \& Brier, T. (1999). Enablers and inhibitors of business-IT alignment. Communications for the Association for Information Systems, 1(11), 133.

Luftman, J. N. (2000). Assessing business IT-alignment maturity. Communications for the Association for Information Systems, 4(14).

Luftman, J. N. (2003). Assessing business-IT alignment. Information System Management, 20(4), 9-15, Autunn.

Luftman, J. N., \& Kempaiah, R. (2007). An update on business-IT alignment: A line has been drawn. MIS Quarterly Executive, 6(3), 165-77.

Luftman, J. N., \& Ben-Zvi, T. (2010). Key issues for IT executives 2009: difficult economy's impact on IT. MIS Quarterly Executive, 9(1), 49-59.

Luftman, J., Zadeh, H. S., Derksen, B., Santana, M., Rigoni, E. H., \& Huang, Z. (2013). Key information technology and management issues 2012-2013: an international study. Journal of Information Technology, 28(4), 354-66.

Maes, R., Rijenbrij, D., Truijens, O., \& Goedvolk, H. (2000). Redefining business - IT alignment through a unified framework. Universiteit van Amsterdan. White Paper.

Malhotra, N. K. (2006). Pesquisa de marketing: uma orientação aplicada. (4a ed.). Porto Alegre, Bookman.

Osterwalder, A., Pigneur, Y., \& Tucci, C. L. (2005). Clarifying business models: origns, present and future of the concept. Communications for the Association for Information Systems, 15, May.

PMI - Project Management Institute. (2003). Organizational project management maturity model: knowledge foundation. Pennsylvania, PMI.

PMI - Project Management Institute. (2012). Site oficial PMI.

PMI - Project Management Institute. (2013). Um guia do conhecimento em gerenciamento de projetos (Guia PMBOK®). (5a ed.). Pennsylvania, PMl.

Pmsurvey.org - Project Management Institute. (2011). Chapters 2011 Edition.

Rabechini Júnior, R. (2005). Competências e maturidade em gestão de projetos: uma perspectiva estruturada. São Paulo, Annablume.

Rigoni, E. H. (2006). Alinhamento estratégico entre negócios e tecnologia de informação: práticas promovidas em empresas industriais na região sul do Brasil. (Dissertação de Mestrado em Administração, UFRGS, Porto Alegre, RS, Brasil).

Sabherwal, R., \& Chan, Y. E. (2001). Alignment between business and IS strategies: a study of prospectors, analyzers and defenders. Information Systems Research, 12(1), 1-33. 
Shenhar, A. (2004). Strategic project leaderships toward a stratify approach to project management. R\&D Management, 34(5), 569-78.

Shenhar, A., \& Dvir, D. (2010). Reinventando gerenciamento de projetos: a abordagem diamante ao crescimento e inovação bem-sucedidos. São Paulo, Makroon Books.

Siqueira, L. D., \& Crispim, S. F. (2014). Alinhamento dos projetos de TI aos modelos de negócio das organizações. Gestão \& Produção, 21(3), 621-34, jul./set.

Sledgianowski, D., Luftman, J. N., \& Reilly, R. R. (2006). Development and validation of an instrument to measure maturity of IT business strategic alignment mechanisms. Information Resources Management Journal, 19(3), 18-33, Jul.Sep.

Tarafdar, M. \& Qrunfleh, S. (2010). Examining tactical information technology business alignment. The Journal of Computer Information System, 50(4), 107-16. 